\title{
Teaching, Technology, And The Art Of The Deal
}

Jeffrey Schieberl, Pepperdine University, USA

Michael Rainey, Pepperdine University, USA

Lynda Palmer, Pepperdine University, USA

\begin{abstract}
This paper illustrates a teaching innovation that took a traditional role playing exercise based on a case study and added some nuances that amplified the learning experience. The example illustrated in this paper was a didactic negotiation exercise intended to teach simple, basic negotiation principles like zone of possible agreement (ZOPA), opening gambit, and the "feel of the deal," but this innovation can be applied to many different types of interactive cases. Traditionally, an exercise like this is conducted in one class; however, in this case study, we enhanced the exercise by using two different classes in two different geographical locations ${ }^{1}$ taught by two different professors with different styles of teaching negotiation. Additionally, students had a choice of technology by which to perform the negotiation and technology was used to bring both classes together for a debriefing session. The end result was an exponential increase in the learning experience. Not only did the students accomplish the key learning objectives of the case, the negotiation principals, but they also were able to experience different negotiation styles taught by the two professors and experience the impact technology has on communication effectiveness.
\end{abstract}

Keywords: Teaching Strategies; Teaching Innovation; Negotiation, Teaching and Technology; Unique Teaching Methods; Enhancing Case Learning

\section{THE EXERCISE}

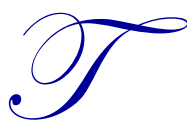

he exercise used was The Salt Harbor Case written by Professor Michael Wheeler. The story takes place in Salt Harbor a quaint town, similar to the Hamptons on Long Island, New York. This vacation spot grew from primarily a summer vacation spot to a year-round resort destination. The salient facts of the conflict are:

Three months ago Brims, a national chain of coffee shops, acquired a parcel of property on which it plans to build and operate a Brims coffee shop. The abutting property to the Brim's lot is the Easterly Bed \& Breakfast Inn. After several years in the business, the Easterly is finally becoming profitable. Previously, the Easterly's primary source of income was the "seasonal" business. Now the Easterly's reputation is such that it is beginning to cater to customers on an annual basis with some of these new clients booking rooms a year in advance. The conflict in the case involves the oddly sized lot purchased by Brims. If Brims develops it, it will obscure the Easterly Inn's view, perhaps causing serious, if not irreparable, damage to their business. The negotiation is between a Brims agent with the authority to make a deal and the owner of the Easterly.

The two (2) confidential fact sheets are attached as Appendix A and Appendix B. They are given to the students who participate so that they can prepare the case for their side.

The exercise is solely about price. The parties are told expressly, "for the sake of this exercise, please do not introduce other issues or terms." "They are also told financing is not an issue-Easterly will take care of the

\footnotetext{
${ }^{1}$ As an interesting aside, one class was in West Los Angeles and the other in Irvine-both very different social and political "cultures." This being said, there was no empirical evidence these differences had any influence on the ultimate results.
} 
financing. All efforts are made to keep the participants focused solely on price and the steps, tactics, and process to achieve their best price. Included in the facts are some attorney prognostications on risks and benefits of various alternatives.

Like a real-world negotiation, the exercise has numerous challenges. It has varying degrees of asymmetric information and plenty of variables, which give rise to uncertainty for the negotiators. What makes this exercise most impactful is how it so closely illustrates real-world situations negotiators face every day. Augmenting the exercise with the challenge of distance, technology, and different teaching styles adds yet another interesting dimension.

\section{EXECUTION OF THE EXERCISE}

This exercise was conducted using two geographically dispersed classes taught by two different professors. Professor Schieberl's Spring 2013 Irvine (IR) class had 13 students. Professor Rainey's Spring 2013 West Los Angeles (WLA) class had 25 students. The distance between the two campuses is about 45 miles, but during high traffic times, it can be a three hour trip.

These students are Fully Employed Masters of Business \& Administration (FEMBA) at Pepperdine University Graziadio School of Business \& Management. In the WLA class, there were two students involved in residential \& commercial real estate and two were involved in law firms. In the IR class, none of the students had subject matter experience they could draw upon. The classes engaged in the Salt Harbor negotiation approximately half way through the semester.

The classes were given the Easterly and the Brims fact sheets (Appendices A and B) and allotted a week to complete the exercise. Because of the disparity in the number of students in each class, negotiation teams were assigned with two students representing Easterly and one student representing Brims. Students were instructed to read the facts carefully and prepare a strategy. When they felt adequately prepared, they were to contact an assigned student partner in the other class and attempt to make a deal.

Students were told they could conduct the negotiation in person, by Facetime, Skype, or, as a last alternative, by phone. Each team was responsible for setting up their meeting and instructed to treat it as a real-world transaction. It would be fair to say in-person negotiations were encouraged, but both professors were interested in any deviations attributed to the mode of the negotiation. After the negotiations were completed, the negotiators were required to provide a written explanation of their results and then the classes debriefed via video conference (see below).

A week after the assignment was completed the students met in their respective classrooms. For the first hour the professors debriefed their students. During the second hour, the classes connected by video conference. The students could talk to their former negotiation "partners." They discussed the nuances of the negotiation, including what worked for them and how they reached their ultimate number. However, it is important to note, although the debriefing seemed complete, the subsequent time in class and the following weeks yielded numerous tid-bits of new information. In essence the learning process appeared to be quite deep, with new information being discussed over several weeks following the exercise.

\section{RESULTS}

One class was almost twice the size of the other class, so one side of negotiators had two people and the other side had one person. This did not seem to create any problems, as most of the 13 teams negotiated a deal within the parameters of the given facts. The deals ranged from No Deal to well over a hundred thousand dollars. Some examples of the discussion of the deals were:

- $\quad$ No Deal-Perhaps the student negotiators in this group collectively misunderstood the assignment. They believed simply getting Easterly to back off a lawsuit, even without a consummated deal, was sufficient. The negotiators believed their agreement, while not involving a cash payment or a change of ownership, involved value that was equivalent of a good cash value. 
- $\$ 110,000$ - This price is not a valid result, as one team of negotiators added facts which were not a part of the given facts, and that, if true, would have substantially reduced the value of the property. ${ }^{2}$

- $\quad \$ 135,000$

- $\quad$ Sale price of land $\$ 183,500$ - Brims Coffee gets first right of refusal if you elect to sell the parcel of land in the future. Market price to be determined by a mutually agreeable sales agent and appraisal agent. Brims Coffee to absorb the cost of creating a copper placard for B \& B and Coffee Shop highlighting efforts of the two businesses to bring a nice gathering place for the community. The relationship was strengthened by the meeting and sale of the parcel of land. Both sides look forward to working together in the future to drive business and provide amenities for the client.

- $\quad$ Primary strategy is to see if owner of Easterly can be induced to drop the charges. If yes to dropping charges you can trade a contract/agreement for the dismissal. If he cannot be induced, pursue second strategy, which is to negotiate to sell original parcel at best price possible. ${ }^{3}$

- $\quad$ The parties intend to engage in a contract wherein Brims will work together with Easterly Inn in the design and architecture of the coffee shop, thereby keeping with the traditional architecture of Salt Harbor without blocking the ocean view room located in the Easterly Inn. In return, Easterly Inn agrees to immediately drop the lawsuit against Brims. Should there be disagreement in the future, both parties agreed to settle the dispute through arbitration or mediation without reverting to litigation.

\section{NEGOTIATORS' COMMENTS}

The following are a few of the student negotiators' comments:

- $\quad$ "Preparation made all the difference in the world. It helped us anticipate the unknown. It made it so much easier."

- $\quad$ "We did a lot to 'break the ice' by engaging in small talk. We wanted to have a rapport with the other side. We think it made a big difference."

- $\quad$ "The other side seemed to be solely focused on price. We tried to find ways of creating added value."

- $\quad$ "We did the negotiation by phone. We started by Google but the technology failed. We adapted and it worked out. We did not realize the difficulty of conducting a complicated negotiation without the accompaniment of the additional 'communication' afforded by body language and facial expression. It was hard."

- "We did the negotiation in person. I would not feel comfortable doing it any other way."

- $\quad$ "They told us there was a major issue with the soil and it substantially affected the price of the property. We did not have this fact and it was presented so well that we believed the other side and adjusted our [offer/demand] accordingly."

- $\quad$ "Our final number was $\$ 110,000$. I felt the negotiation was helpful for me since we were put in a different environment. I was only unclear about whether certain critical information was being withheld from one of the parties." (In our case, the issue of the soil problem came up). "I realized afterwards that probing more during the negotiation process probably would have limited the effect of this misinformation being mentioned during our negotiation. Overall, I felt the negotiation was effective and helped me better understand certain tactics to use in order to be more efficient while negotiating. Thank you."

- $\quad$ "The only comments I would add are that each side seem to genuinely be pleased with the result and each side seem to perceive 'value' differently. Options such as an exclusive supplier of coffee or an offer to allow Brims to install and operate a kiosk — or an offer from Brims to B \& B for cross marketing were all rejected. Either because seen as too risky (first two items mentioned above) or unnecessary (last item above-at least that was what was expressed). I believe meeting in person increased the learning experience exponentially."

- $\quad$ "If we had not taken the time to get to know 'him' and his 'business' and what winning looked like for him, we would not have been able to find the best case scenario for both sides. Despite how it was regarded as a

\footnotetext{
${ }^{2}$ One of the students introduced extraneous and erroneous "evidence" that the soil was polluted and constituted an environmental risk. This was reflected in the ultimate sales price.

${ }^{3}$ This negotiating team apparently did not understand the assignment and/or did not completely read the factual scenario.

${ }^{4}$ There was no "soil problem." This was inserted by one of the parties, on their own.
} 
'no deal' situation, the other team and our team are actually very proud of the results. After we reached this deal, we then also had time to come up with a backup plan of $\$ 135,000$ just in case senior management of 'our' company did not agree with the first deal. We took our time and it still took only 45 minutes to complete. All in all, it was a great experience for us. I hope we will have more chances to do similar negotiations before the end of the trimester."

\section{KEY OBSERVATIONS}

Both professors agree the exercise was successful and beneficial. Not only did the students get a chance to apply the negotiation concepts they learned in class, but they also were able to experience opponents who had been taught a different style of negotiation.

These two professors have distinctly different styles of teaching negotiation. The students observed one class appeared to focus on tactics and price and the other class seemed to emphasize value and technique; i.e., probing, listening to responses, and then adapting their approach. In the end, it was universally agreed these styles were different facets of the same "stone" and generally yielded desirable results—a final sale price. Previously this exercise was run using a single class.

Another key takeaway was the impact the modality had on the negotiation results. Although all the students on a respective side had the same facts, each negotiating team had the choice of different means of conducting the negotiation. Then they had the opportunity to discuss the benefits and detriments of each mode of communication.

Travel to a face-to-face meeting required the time to adjust schedules for three people, plus the time and cost of a trip to meet the other team. Facetime, Skype, and Google were generally preferred over using the phone, but they also illustrated the difficulties of using technology. Sometimes it fails. Sometimes it is intermittent. Sometimes the quality of the experience is far less than acceptable. Students learned to think on the fly, which is another valuable lesson. Finally, the students who decided to use the phone were both surprised with what they learned from this medium and disappointed with what they missed by using solely a phone for such critical negotiations.

\section{CONCLUSION}

An in-class negotiation exercise is a great way for students to observe and experience all the complexities, vagaries, and unforeseeable aspects of a negotiation. However, enhancing the exercise with technology and different teaching styles exponentially increased the impact and value of the learning. The students experienced different negotiation styles and the impact of those styles on the process and, ultimately, the outcome. They were then able to delve deeper into understanding the different styles by debriefing first in their own class, then with their opponents. Finally, comparing and contrasting the outcomes using the different modalities is a great hands-on way for the students to cope with the diversity of teaching style, understand how to handle unpredictable events, and learn the impact of technology on negotiation.

Conducting a hands-on, interactive exercise using two classes in remote locations can be adapted to many business courses. The impact of the exercise is robust and professors using an exercise like this should be constantly sensitive to the new information stemming from the exercise being shared by the students throughout the term.

\section{AUTHOR INFORMATION}

Professor Jeffrey Schieberl teaches law, negotiations, ethics, and management courses in the undergraduate, graduate, online, and executive programs at Pepperdine University. He has served as President/CEO of a corporation, Vice President of Law and Government Relations of another corporation, Executive Director of an Industry Association, and as a gubernatorial appointee. In addition, Professor Schieberl maintains an active consulting practice. In those capacities he has made numerous presentations to members of Congress, several state legislatures and business organizations. E-mail: Jeff.Schieberl@ pepperdine.edu 
Dr. Michael B. Rainey has been a Pepperdine faculty member since 1998. Dr. Rainey teaches Business Law, Dispute Resolution, Ethics, and Critical Thinking at the Graziadio School of Business \& Management and coaches the Pepperdine University School of Law, ABA Mediation Competition teams. A litigating attorney for thirty (30) years, his practice is now exclusively Mediation \& Arbitration. E-mail: Michael@michaelrainey.com (Corresponding author)

Professor Lynda Palmer has been a Pepperdine faculty member since 1993. Professor Palmer teaches graduate and undergraduate marketing courses in online, blended, and face-to-face formats at the Graziadio School of Business \& Management. She is also the Case Development Manager of Pepperdine's acclaimed Education to Business (E2B) program and provides strategic marketing consulting to clients in the automotive and equestrian industries. E-mail: Lynda.palmer@pepperdine.edu

\section{REFERENCES}

1. Wheeler, M. (2001). The salt harbor case. Harvard Business School Publishing. 


\section{APPENDIX A}

\section{Salt Harbor: Confidential Information for Easterly ${ }^{5}$}

You are the owner of the Easterly, a successful bed and breakfast inn, located in the picturesque seaside village of Salt Harbor. You purchased the old hotel almost 20 years ago, partly as an investment and partly to restore the old sea captain's house to its former glory.

Your task today is to try and negotiate the purchase of the adjoining piece of undeveloped land. Here is the key background information.

You operated the Easterly at a loss for a number of years. The old structure needs a lot of repairs and it was hard to find capable staff. Over the past decade, Salt Harbor experienced a real revival and you had the good fortune to hire a manager who did an excellent job building the reputation of the inn. Some of your guests now make reservations a full year in advance to enjoy Salt Harbor in the prime season. The inn is now busy most of the year.

As a result, you have actually made a profit in recent years. Moreover, the value of your real estate increased substantially, even after taking into account the investments you made for improvements.

In the midst of this success you are facing a new challenge. Brims, a regional chain of coffee shops, bought the vacant parcel of land on the side of your inn that faces the harbor. Brims already filed for a permit to build a $1 \frac{1}{2}-$ story structure that would block the view from the inn's porch and some of the best rooms. While the operators of Brims pledged their building will be "in keeping with the character" of Salt Harbor, you have no doubt it will have serious, detrimental impact on your inn.

With 20-20 hindsight, you wish you had purchased the lot at the same time you bought the Easterly, but the reality is your finances were stretched at the time, and it made much more sense to put what money you had into refurbishing the old inn. This past year you simply did not know the parcel was on the market.

You have always been under the impression that because the lot was small, it was unbuildable-that is, that it did not meet the minimum size requirements set by local zoning ordinances. The lawyer you consulted told you that you may be correct. Acting on her advice, you intend to file a formal objection to the issuance of the building permit to Brims. Such challenges are heard by various municipal regulatory boards and can end up in court if the use permit seeker or the challengers are dissatisfied with the local rulings.

The zoning dispute, in a nutshell, is Brims claims that because a lot they purchased was created before the current zoning ordinances came into effect, it is "grandfathered" in as a legal lot. In other words, Brims argues that because the lot was legal when it was split off from the adjoining parcel it is legal now.

Your lawyer advised you Brims would be correct if they were proposing a residential use, but the ordinance is ambiguous, at best, about whether "grandfathering" also applies to commercial uses. She said you have about a 50 percent chance of ultimately stopping the issuance of a building permit to Brims for construction of their new coffee shop. She also cautioned you that going through local regulatory procedures, a trial, and possible appeal could take several years and cost at least $\$ 25,000$ in legal fees, perhaps more. She reminded you that you are not sure of winning. Moreover, even if you blocked their building permit, Brims could sell the land and someone else would be authorized to build a single-family house. Any structure - coffee shop or a house-would irreparably interfere with your inn's views and substantially diminish the value of your property.

As a result she has urged you to try and purchase the lot from Brims before either side sinks too much money into a legal fight over zoning issues. She worked carefully with you to prepare your negotiation. You do not want to pay more than necessary to acquire the parcel. Unless Brims is demanding a completely unreasonable price, you believe it would be better to buy the lot from them than to run the risk (and bear the cost) of going to court.

\footnotetext{
${ }^{5}$ Michael A. Wheeler "Salt Harbor: Confidential Information for Easterly." Harvard Business School Exercise 800-077, June 2002. (Revised from original December 1999 version.) It was modified by Michael Rainey 2012-1013
} 
It is impossible to get a definitive appraisal of the value of the parcel. Its small size and the unresolved zoning issue make it unique. In the end, its value can only be set by what a willing buyer and willing seller agree on. The only reason to buy the land is to prevent someone else from building on it. If you buy the parcel, you will landscape it nicely, but you do not believe there is much more you can do with it. To help you plan for the negotiations, you confirmed the following prices:

1. $\$ 100,000$ : is the amount Brims paid for the parcel three months ago. This is pretty close to the current value of the parcel as a residential building lot. Depending on the real estate market, this could be higher or lower in several years if you were to wait for a final court ruling to vindicate your legal position.

2. $\$ 200,000$ : is your guess about how much Brims would have to pay for comparable site in the village of Salt Harbor. Your guess could be high or low by quite a bit.

3. $\$ 350,000,+$ or $-10 \%$ : is the difference in value of the Easterly between having its current water views, or losing them if something is built on the neighboring lot. This number takes into account reduced rent that you can charge, loss of property value itself, as well as a subjective factor reflecting your own sense of disappointment if the views are lost.

The meeting is arranged with a representative from Brims. You should make it clear to them you are not prepared to drop your legal challenge to their building permit. By the same token, you understand they are unlikely to simply drop their project unless they are paid a reasonable value for the land they recently bought.

Your assignment is to purchase their land at the best possible price. For the sake of the exercise, please do not introduce other issues or terms. Simply try to reach agreement on price. Your respective lawyers can handle the legal technicalities, and you will arrange your own financing. Completing the attached form is part of your preparation, but do not show it or the facts to the other side. Good luck. 
Your Name

The following questions are intended to crystallize your thinking about what price you might negotiate to sell the land to the Easterly. In planning for your meeting with them, you may well want to think about other issues, as well. Please be ready to discuss at least these questions.

1. Who makes the $\mathbf{1}^{\text {st }}$ offer? After preliminary conversation, someone will likely have to put the first serious figure on the table, either you or the Brims representative. Do you want to make the first offer?
A. Definitely yes
B. Probably yes
C. Don't care
D. Probably no
E. Definitely no

2. Who made the first offer and why?

3. What is the $\mathbf{1}^{\text {st }}$ offer? Regardless of your preferences, if you did put the first serious number on the table, what amount would you offer?

4. What is the very best price you realistically hope to acquire?

5. What specific price would be a good outcome?

6. "Walkaway" price? Given the information in the case, what is the absolute least you will except for the land? That is, if Brims were to insist on $\$ 1$ less than the amount, you would reluctantly abandoned the negotiation and pursue other alternatives. In other words, what do you think is their BATNA?

7. Did you discuss strategy with your partner prior to the exercise? Did you originally want to make the first offer?

8. What was the first offer? If you were the party to make the first offer what do you think their first offer would have been if they presented it?

9. What was your BATNA?

10. Did your strategy change throughout the negotiation?

11. How many counteroffers were there? What was the pace of concessions or counteroffers? What were the counter offers and how did you come up with that offer?

12. How long did the negotiation take? Was it too long or too short? How did the length of time impact the negotiation?

REMEMBER, do not show this sheet or the company facts to the person you will be negotiating with. Good luck and have fun. 


\section{APPENDIX B}

\section{Salt Harbor: Confidential Information for Brims ${ }^{6}$}

You are the regional manager for Brims, a highly regarded and fast-growing chain of coffee shops. Three months ago, Brims acquired a parcel of property in the resort community of Salt Harbor. It planned to build and operate a new shop as soon as possible. For reasons explained below, your task today is to try to negotiate the sale of the same parcel. Here is the key background information.

The Salt Harbor market is extremely promising. Although it was once mainly a summer vacation spot, it has become popular in all seasons. Although there are number of local restaurants and bakeries, currently there is no direct competition with a Brims type of store, so now is an opportune time to open one or more shops in the area.

Brims developed shops in similar communities, so they were not surprised when the planned opening drew mixed reactions. Many people seem to welcome the prospect of a purveyor of fine coffee and pastries and others are happy jobs will be created and the tax base enhanced. As often is the case, there is also some opposition. There is some grumbling about the impact of "chains" on local business and the potential loss of "community character." As Brims' representative, you have had success in persuading some of these skeptics that Brims is not a fast food operation and that Brims' new shop will be in keeping with the town's traditional architecture.

You were disappointed to learn the issuance of your building permit was formally challenged by the owner of the Easterly, a bed and breakfast inn located adjacent to the parcel Brims just purchased. Easterly's owner contends your parcel is smaller than the minimum required by zoning, hence is not buildable. Appeals through the local regulatory board could take months. Even if Brims prevails before the regulatory board, Easterly could then take their claim to court where it might well be years before the dispute is definitively resolved.

Brims' corporate lawyers and their outside experts advised you Brims has a strong case. While it is true the parcel is smaller than the current zoning requires, the lot was fully legal when it was originally carved out of the other piece of land. A state statute provides such lots are "grandfathered," meaning they remain legal even if subsequent zoning becomes more restrictive. It was on this understanding Brims bought the land several months ago.

Now that the Easterly owner brought this challenge, Brims' lawyers began to research the issue. They are confident the state statute protects your lot for residential use, but they are concerned that there is a little ambiguity about whether commercial uses are also grandfathered. This is the specific point the Easterly owner raised. In spite of this ambiguity, the lawyers believe Brims has at least an 80 percent chance of prevailing if this matter goes to trial and is subsequently appealed. This opinion gives you no real comfort. Brims cannot wait months-or years-to open a shop. Unless the owner of the Easterly can be induced to drop the challenge to Brims' building permit immediately, Brims must "unload" this parcel at the best price, as soon as possible, and move quickly to acquire and develop another site. (If there is any good news in all of this, it is someone else in your organization was responsible for buying this "tainted" parcel next to the Easterly. Anything that you can do to untangle this mess will clearly be to your credit in the company.)

It is difficult to know what is motivating the Easterly owner. The Easterly is a bed and breakfast inn and it is difficult to see how your operation would adversely affect their business. It may be they are concerned your structure will interfere with the inn's view of the harbor. In your opinion, if Easterly did not care enough about their view to protect themselves by buying the parcel, they should not tell other people what to do with their own land.

In any event, the meeting with the Easterly owner is about to take place. In the best of all worlds, perhaps you can persuade them to drop their legal challenge. You definitely should not offer to pay them for doing so. This is a small town, and if word gets out the Easterly owner was "paid off," then other "interested citizens" might well

\footnotetext{
${ }^{6}$ Michael A. Wheeler "Salt Harbor: Confidential Information for Easterly." Harvard Business School Exercise 800-077, June 2002. (Revised from original December 1999 version.) It was modified by Michael Rainey 2012-1013
} 
pop up and make similar demands. In other words, paying off the Easterly owner has some down sides and would not insulate Brims from a lawsuit or guarantee them a right to build a coffee shop.

The most realistic option seems to be selling the parcel to the Easterly owner before both of you invest too much money (and time) in regulatory and legal expenses. Indeed, you have already identified and alternative site for a shop. It is equally attractive, though somewhat more expensive. As a result, if Brims sells the original parcel to the Easterly owner, they want to get as good a price as possible. Brims does not want to put more money into their pockets than necessary.

So far, it has been impossible to get a definitive appraisal of the value of the disputed parcel. Its small size and unresolved zoning issues make the property unique. Ultimately, its value can be only set by a willing buyer and a willing seller who agree on a price. To help you plan for your negotiation, you have confirmed the following figures.

1. $\$ 100,000$ : is the amount Brims paid for the parcel three months ago. At that time, this seemed to be an excellent price. The company paid $\$ 10,000$ more in associated costs.

2. $\$ 125,000(+$ or $-20 \%)$ : is the current value of the land as a residential lot. There is no doubt in your lawyer's mind the lot is legal for residential purposes. It is possible the current dispute over the building permit might be misunderstood by some people and thus discourage some potential buyers.

3. $\$ 165,000$ : is the likely cost of an alternative site for your new Brims shop.

4. $\$ 20,000$ : is the estimated additional legal costs of defending a building permit before the local regulatory boards and the trial; a subsequent appeal would cost more.

Your assignment is to try and sell the original parcel at the best price possible. If you are unable to make a deal with the owner of the Easterly, you will put the property on the market and try to sell it as a residential lot. For the sake of this exercise, please do not introduce other issues or terms. Simply try to reach an agreement on a cash price. Your respective lawyers can handle the legal technicalities. The Easterly will arrange their own financing. Complete the attached form as part of your preparation, but do not show it (or these facts) to the other side. Good luck! 
Your Name

The following questions are intended to crystallize your thinking about what price you might negotiate to sell the land to the Easterly. In planning for your meeting with them you may well want to think about other issues, as well. Please be prepared to talk about at least these questions.

1. Who makes the $\mathbf{1}^{\text {st }}$ offer? After preliminary conversation, someone will likely have to put the first serious figure on the table, either you or the Easterly representative. Do you want to make the first offer?
A. Definitely yes
B. Probably yes
C. Don't care
D. Probably no
E. Definitely no

2. Who made the first offer and why?

3. What is the $\mathbf{1}^{\text {st }}$ offer? Regardless of your preferences, if you did put the first serious number on the table, what amount would you offer?

4. What is the very best price you realistically hope to acquire?

5. What specific price would be a good outcome?

6. "Walkaway" price? Given the information in the case, what is the absolute least you will except for the land? That is, if Easterly were to insist on $\$ 1$ less than the amount, you would reluctantly abandoned the negotiation and pursue other alternatives. In other words, what do you think was their BATNA?

7. Did you discuss strategy with your partner prior to the exercise? Did you originally want to make the first offer?

8. What was the first offer? If you were the party to make the first offer what do you think their first offer would have been if they presented it?

9. What was your BATNA?

10. Did your strategy change throughout the negotiation?

11. How many counteroffers were there? What was the pace of concessions or counteroffers? What were the counter offers and how did you come up with that offer?

12. How long did the negotiation take? Was it too long or too short? How did the length of time impact the negotiation?

REMEMBER, do not show this sheet or the company facts to the person you will be negotiating with. Good luck and have fun. 
NOTES 